\title{
Roles of the H19/microRNA-675 axis in the proliferation and epithelial-mesenchymal transition of human cutaneous squamous cell carcinoma cells
}

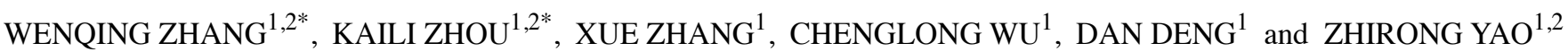 \\ ${ }^{1}$ Department of Dermatology, Xinhua Hospital, School of Medicine, Shanghai Jiao Tong University; \\ ${ }^{2}$ Institute of Dermatology, School of Medicine, Shanghai Jiao Tong University, Shanghai 200092, P.R. China
}

Received October 30, 2020; Accepted January 15, 2021

DOI: $10.3892 /$ or.2021.7990

\begin{abstract}
The long non-coding RNA (lncRNA) H19 and microRNA(miR)-675 were reported to serve an important role in the tumorigenesis and metastasis of numerous cancer types by promoting the epithelial-mesenchymal transition (EMT) process; however, the underlying mechanisms of action of H19 and miR-675 in cutaneous squamous cell carcinoma (cSCC) remain unknown. The mRNA expression levels of H19 and miR-675 were analyzed using reverse transcription-quantitative PCR, and Cell Counting Kit-8, wound healing and Transwell assays were performed to analyze the cell proliferation, migration and invasion of cSCC cells, respectively. The levels of cell apoptosis were also determined using a TUNEL assay. Protein expression levels of p53 and marker proteins related to the EMT process were analyzed using western blotting. In addition, a dual luciferase reporter assay was performed to determine the interactions between H19, miR-675 and p53. The results of the present study revealed that the expression levels of H19 and miR-675 were upregulated in cSCC tissues and cSCC cell lines. The knockdown of H19 or miR-675 expression inhibited cell proliferation, migration and invasion, but induced cell apoptosis. In addition, the expression levels of EMT-related markers were also downregulated. The overexpression of H19 upregulated the expression levels of its predicted target, miR-675, which subsequently promoted the EMT process and downregulated the expression levels of p53. Conversely, the genetic silencing of $\mathrm{H} 19$ or miR-675 inhibited proliferation and invasion in SCL1 and A431 cSCC cell lines. In conclusion, the findings of the present study provided novel insight into the potential role of $\mathrm{H} 19$ and miR-675 in the
\end{abstract}

Correspondence to: Dr Zhirong Yao, Department of Dermatology, Xinhua Hospital, School of Medicine, Shanghai Jiao Tong University, 1665 Kongjiang Road, Shanghai 200092, P.R. China E-mail: dermatology.yao@sohu.com

*Contributed equally

Key words: long non-coding RNA H19, microRNA-675, cutaneous squamous cell carcinoma, p53, epithelial-mesenchymal transition development, metastasis and progression of cSCC, which may help the development of treatments for cSCC.

\section{Introduction}

Cutaneous squamous cell carcinoma (cSCC) is the second most common type of non-melanoma skin cancer (1). cSCC has been revealed to develop from a pre-malignant condition, such as actinic keratosis (AK) or Bowen's disease (BD) $(2,3)$. Several risk factors have been closely associated with the incidence of cSCC, such as ultraviolet (UV) radiation, smoking, and chemical and air pollutants (4). In particular, UV radiation induces DNA damage in cells and genetic mutations in genes such as p53, which was discovered to result in abnormalities in cell migration, invasion and metastasis (5). Mutations in p53 have been regarded as a pathological mechanism of UV radiation-induced $\mathrm{AK}$ and $\mathrm{BD}$, and it has been hypothesized that the early alterations due to UV damage may promote the tumorigenesis and progression of cSCC (6). Although multiple risk factors are associated with a high susceptibility to $\mathrm{cSCC}$ development, the exact molecular mechanisms underlying human cSCC progression remain unknown. In total, approximately $5 \%$ of patients with cSCC are diagnosed with lymph node metastasis or metastasis in other organs (7). The conventional treatments of cSCC currently include surgical intervention, radiotherapy and chemotherapy; however, the prognosis of metastatic cSCC remains poor with a 1 year survival rate of $44-56 \%$ (8).

Long non-coding RNAs (lncRNAs) are non-protein coding transcripts of $>200$ nucleotides in length (9). Increasing evidence has reported that lncRNAs serve a crucial role in the tumorigenesis and progression of numerous types of cancer, and have exhibited both oncogenic or tumor-suppressive functions $(10,11)$. H19, located on chromosome $11 \mathrm{p} 15.5$, is a long non-coding RNA (lncRNA) which was initially termed as an oncofetal transcript (12). The aberrant expression of H19 was revealed to participate in the pathogenesis of several types of human cancer, including bladder, breast, thyroid and hepatocellular carcinoma (13-15). In addition, a previous study suggested that H19 may be regarded as a biomarker for numerous types of cancer and a potential therapeutic target (16). Several recent studies have demonstrated that H19 served as an oncogene. For example, in cholangiocarcinoma, 
H19 exerted its oncogenic role via sponging let-7a/let-7b to regulate cell migration and invasion (17). In colorectal cancer, the overexpression of $\mathrm{H} 19$ and microRNA (miRNA/miR)-138 promoted the migration and invasion of colorectal cancer cells and upregulated the expression levels of high mobility group AT-hook 1 (HMGA1) (18). In addition, H19 altered the expression levels of cascades of epithelial-mesenchymal transition (EMT)-related makers to promote the proliferation, migration and invasion of melanoma cancer cells, which was suggested to influence the prognosis (19). Furthermore, H19 was reported to function as a precursor of miR-675 which was reported in several cancers types, including breast, non-small cell lung cancer and colon cancer (20). H19 can generate miR-675 in a classic manner depending on Drosha and Dicer splicing, and is located in exosomes, such as endosome-derived extracellular vesicles containing proteins, lipids and RNAs $(21,22)$. However, the pathogenic mechanisms of H19 in cSCC remain poorly understood. The present study hypothesized that $\mathrm{H} 19$ may promote $\mathrm{cSCC}$ tumorigenesis and metastasis and regulate cSCC cell migration and invasion.

In the present study, the expression levels of H19 in clinical sample tissues from patients with cSCC were analyzed, and the potential functional role of $\mathrm{H} 19$ in $\mathrm{CSCC}$ was also investigated. The expression levels of H19 and miR-675 were explored in SCC cell lines. In addition, the potential molecular mechanisms underlying the effects of H19 and miR-675 on the EMT process in cSCC were investigated. To the best of our knowledge, the present study provided the first evidence of the interaction between H19, miR-675, p53 and the EMT process in $\mathrm{CSCC}$, and highlighted the potential oncogenic role of the H19/miR-675 axis in cSCC.

\section{Materials and methods}

Patient studies. A total of 60 paired cSCC adjacent normal tissues were collected from patients with $\mathrm{CSCC}$ at the Department of Dermatology, Xinhua Hospital (Shanghai, China) between January, 2018 and August, 2020. The medical records of the patients were retrospectively reviewed for inclusion and exclusion criteria. The inclusion criteria were as follows: i) Patients who suffered from cSCC; ii) first onset without any prior treatment; and iii) patients who had a complete and standardized postoperative pathology report and follow-up information. The exclusion criteria were as follows: i) Patients who had undergone systemic or local therapy prior to surgical resection, preoperative radiotherapy or chemotherapy or immunotherapy and incomplete medical records; ii) patients who suffered from other skin diseases concurrently; and iii) patients who lacked a complete and standardized postoperative pathology report and follow-up information. The patients had an average age of $68 \pm 16.20$ (range, 36 to 97 years); 29 patients were male (age range, 36 to 89 years) and 31 patients were female (age range, 42 to 97 years). The present study protocol was approved by The Human Ethics Committee at our institute. The acquisition and storage of tissues was approved by the Ethics Committee of Xinhua Hospital, School of Medicine, Shanghai Jiao Tong University (Shanghai, China). Written informed consent was obtained from all the patients prior to participation, and the study was conducted according to the principles of the Declaration of Helsinki. All collected samples were snap frozen in liquid nitrogen and then stored at $-80^{\circ} \mathrm{C}$ until required for further experimentation.

Cell lines and culture. cSCC cell lines, SCL1 (cat. no. CC-Y1669) and A431 (cat. no. CC-Y1033), and the keratinocyte cell line, HaCaT (cat. no. CC-Y1177), were obtained from Ek-Bioscience; all cells were mycoplasma-free. A431 and $\mathrm{HaCaT}$ cells were cultured in DMEM (Gibco; Thermo Fisher Scientific, Inc.), while SCL1 cells were cultured in RPMI-1640 medium (Gibco; Thermo Fisher Scientific, Inc.). All cells were supplemented with 10\% FBS (Gibco; Thermo Fisher Scientific, Inc.) and $1 \%$ penicillin-streptomycin (Invitrogen; Thermo Fisher Scientific, Inc.). All cell lines were incubated in a humidified incubator containing $5 \% \mathrm{CO}_{2}$ at $37^{\circ} \mathrm{C}$.

Cell transfection. Specific small interfering RNAs (siRNAs) targeting H19 (20 nM H19-siRNA-1 and 20 nM H19-siRNA-2), $20 \mathrm{nM}$ p53-siRNA, $20 \mathrm{nM}$ negative control (NC) siRNA, $3 \mu \mathrm{g}$ pcDNA3.1-control plasmids, $3 \mu \mathrm{g}$ pcDNA3.1-H19 and $3 \mu \mathrm{g}$ pcDNA3.1-p53 overexpression plasmids were all designed and synthesized by Hanbio Biotechnology Co.,Ltd. miR-675 mimic $(50 \mathrm{nM})$ and miR-675 inhibitor oligonucleotides $(100 \mathrm{nM})$, as well as mimic-NC $(50 \mathrm{nM})$ and inhibitor-NC $(100 \mathrm{nM})$, were synthesized by Guangzhou RiboBio Co., Ltd. Cells were plated in 6-well plates $\left(1 \times 10^{5}\right.$ cells/well $)$ and incubated at $37^{\circ} \mathrm{C}$ and $5 \% \mathrm{CO}_{2}$ until the cells reached $60-70 \%$ confluence. Then cells were transfected with equal concentrations of oligo fragments diluted in Opti-MEM/reduced serum medium (Gibco; Thermo Fisher Scientific, Inc.) using Lipofectamine ${ }^{\circledR} 3000$ reagent (Invitrogen; Thermo Fisher Scientific, Inc.) according to the manufacturer's instructions. Once the two solutions were mixed and incubated for $5 \mathrm{~min}$ at room temperature, the mixture was plated into a six-well plate. After incubation for $3 \mathrm{~h}$ at $37^{\circ} \mathrm{C}, 1 \mathrm{ml}$ of DMEM containing $10 \%$ FBS and no antibiotics was added to each well. Subsequently, media were replaced with normal growth media $24 \mathrm{~h}$ after transfection. The sequences are listed in Table I.

RNA extraction and quantitative real-time polymerase chain reaction (RT-qPCR) analysis. Total RNA was extracted from the tissues and cells for the generation of single-stranded cDNA using TRIzol reagent (Invitrogen; Thermo Fisher Scientific, Inc.). The first complementary deoxyribonucleic acid (cDNA) strand of H19 was synthesized using an EZ-press RNA Purification kit (EZBioscience). The reverse transcription of miR-675 was performed using the miRNA 1st Strand cDNA Synthesis kit (Vazyme Biotech Co., Ltd.) according to the manufacturer's protocol. Reverse transcription conditions were as follows: $42^{\circ} \mathrm{C}$ for $15 \mathrm{~min}$ and $95^{\circ} \mathrm{C}$ for $1 \mathrm{~min}$. Quantitative PCR was subsequently performed using the 2X SYBR Green qPCR Master mix (EZBioscience) on a QuantStudio $^{\text {TM }} 3$ Real-Time PCR system (Applied Biosystems; Thermo Fisher Scientific, Inc.). The thermocycling conditions were as follows: Hot-start DNA polymerase activation $\left(95^{\circ} \mathrm{C}\right.$, $5 \mathrm{~min}) ; 40$ cycles $\left(95^{\circ} \mathrm{C}, 15 \mathrm{sec}\right.$; and $\left.60^{\circ} \mathrm{C}, 30 \mathrm{sec}\right)$; and last melt curve analysis $\left(95^{\circ} \mathrm{C}, 15 \mathrm{sec} ; 60^{\circ} \mathrm{C}, 1 \mathrm{~min} ; 95^{\circ} \mathrm{C}, 30 \mathrm{sec}\right.$; and $\left.60^{\circ} \mathrm{C}, 15 \mathrm{sec}\right)$. The following primer pairs were used for the qPCR: H19 forward, 5'-CTCCCTCTTCTTCTTTTT CATC-3' and reverse, 5'-CGCACACTCGTACTGAGACT-3'; miR-675-5p forward, 5'-TTGGTGGTGCGGAGAG-3' and 
Table I. Sequences designed for the study.

Name

Sequences (5'-3')

H19-siRNA-1
H19-siRNA-2
p53-siRNA
NC-siRNA
H19
p53

pcDNA3.1-NC

miR-675-5p mimics

$\mathrm{NC}$ for the miR-675-5p mimics

miR-675-5p inhibitors

$\mathrm{NC}$ for the miR-675-5p inhibitors

CUGGACUCAUCAUCAAUAA
GAACCCACAACAUGAAAGA
GACUCCAGUGGUAAUCUAC
UUCUCCGAACGUGUCACGU
CAGCCCAACATCAAAGACA
GAGGTTGGCTCTGACTGTACC
CTAGAGAACCCACTGCTTAC
UGGUGCGGAGAGGGCCCACAGUG
UUUGUACUACACAAAAGUACUG
CACUGUGGGCCCUCUCCGCACCA
CAGUACUUUUGUGUAGUACAAA

CUGGACUCAUCAUCAAUAA

GAACCCACAACAUGAAAGA

GACUCCAGUGGUAAUCUAC

UUCUCCGAACGUGUCACGU

CAGCCCAACATCAAAGACA

GAGGTTGGCTCTGACTGTACC

CTAGAGAACCCACTGCTTAC

UGGUGCGGAGAGGGCCCACAGUG

CAGUACUUUUGUGUAGUACAAA

siRNA, small interfering RNA; NC, negative control; miR, microRNA.

reverse, 5'-AGTGCGTGTCGTGGAGTC-3'; $\beta$-actin forward, 5'-AAGGTGACAGCAGTCGGTT-3' and reverse, 5'-TGTGTG GACTTGGGAGAGG-3'; and U6 forward, 5'-CTTCGGCAG CACATATACTA-3' and reverse, 5'-AACTGGTGTCGTGGA GTC-3'. Relative expression levels were calculated using the $2^{-\Delta \Delta \mathrm{Cq}}$ method (23). $\beta$-actin was used as the reference gene for IncRNA and mRNA, and U6 was the internal reference gene for miRNA. Experiments were repeated $\geq 3$ times with five replicate wells per sample.

Western blotting. Proteins were extracted from cells with RIPA lysis buffer (Beyotime Institute of Biotechnology). Total protein was quantified using a BCA protein assay (Beyotime Institute of Biotechnology) with multi-volume spectrophotometer system (Epoch; BioTek Instruments, Inc.) and proteins (40 $\mu \mathrm{g})$ were separated via 10\% SDS-PAGE. The separated proteins were subsequently transferred onto PVDF membranes (EMD Millipore) and blocked with 10\% non-fat milk for $1 \mathrm{~h}$ at room temperature. The membranes were then incubated with the following primary antibodies overnight at $4^{\circ} \mathrm{C}$ : Anti-p53 (1:1,000; product no. 9282T; Cell Signaling Technology, Inc.), anti-Bax (1:1,000; product no. 2772T; Cell Signaling Technology, Inc.), anti-Bcl-2 (1:1,000; product no. 4223T; Cell Signaling Technology, Inc.), anti-E-cadherin (1:1,000; product code ab231303; Abcam), anti-vimentin (1:1,000; product code ab92547; Abcam), anti-N-cadherin (1:1,000; ab76011; Abcam) and anti-GAPDH (1:1,000; product no. AF1186; Beyotime Institute of Biotechnology). The following day, the membranes were washed with TBST three times (10 min each) and incubated with secondary antibodies (anti-rabbit) (1:1,000; product no. A0208; Beyotime Institute of Biotechnology) at room temperature for $1.5 \mathrm{~h}$. Protein bands were visualized using an ECL kit (Beyotime Institute of Biotechnology). ImageJ software 1.8.0 (National Institutes of Health) was used to quantify the integrated density of the bands.

Cell Counting Kit-8 (CCK-8) assay. Cell proliferation was analyzed using a CCK-8 assay (Dojindo Molecular Technologies, Inc.) according to the manufacturer's protocol. Briefly, transfected cells were seeded into 96-well plates $\left(5 \times 10^{3}\right.$ cells/well) and incubated for $24,48,72,96$ or $120 \mathrm{~h}$. Following the incubation, CCK- 8 reagent (10 $\mu \mathrm{l} / \mathrm{well})$ was added to each well at $37^{\circ} \mathrm{C}$. The optical density (OD) values were detected at a wavelength of $450 \mathrm{~nm}$ using a microplate reader (Bio-Rad Laboratories, Inc.) after $2 \mathrm{~h}$. Experiments were repeated $\geq 3$ times with five replicate wells per sample.

Wound healing assay. Cells were seeded into six-well plates at a density of $2.0 \times 10^{5}$ cells/well to determine the migratory ability. Upon the cells reaching $80-90 \%$ confluence, a $100-\mu 1$ pipette tip was used to produce a single scratch in the cell monolayer of each well; PBS was used to remove the non-adherent cells following scratching. The cells were subsequently cultured in fresh culture medium in an incubator at $37^{\circ} \mathrm{C}$. An inverted microscope was used to observe the migratory distance of the cells into the scratch area at 0,12 and $24 \mathrm{~h}$. The assay was repeated three times.

Transwell migration and invasion assays. Transwell migration and invasion assays were performed using a Transwell chamber (Corning, Inc.). Briefly, transfected cells at a density of $5.0 \times 10^{4}$ suspended in serum-free medium were seeded into the upper chamber of the Transwell plate. The lower chambers were filled with $500 \mu$ l RPMI-1640 medium supplemented with $12 \%$ fetal bovine (FBS) serum. Following incubation for $24 \mathrm{~h}$ at $37^{\circ} \mathrm{C}$, the cells remaining in the upper chamber were removed, while the cells in the lower chamber were fixed with $4 \%$ paraformaldehyde for $15 \mathrm{~min}$ and stained with $0.1 \%$ crystal violet at room temperature for $30 \mathrm{~min}$. An inverted light microscope (Olympus Inverted Microscope) was used to count cell migration/invasion in randomly selected fields of view to semi-quantify the mean migration and invasion distances. Invasion assays were conducted in accordance with the aforementioned procedures except that the lower chambers were precoated with the diluted Matrigel. After incubation for $24 \mathrm{~h}$ for migration and $20 \mathrm{~h}$ for invasion at $37^{\circ} \mathrm{C}$, the cells on the upper surface were wiped off and cells on the lower surface were stained with $0.1 \%$ crystal violet at room temperature for $30 \mathrm{~min}$. The average number of migrated and invasive cells was counted and photographed under a light microscope (magnification, x200). 
A
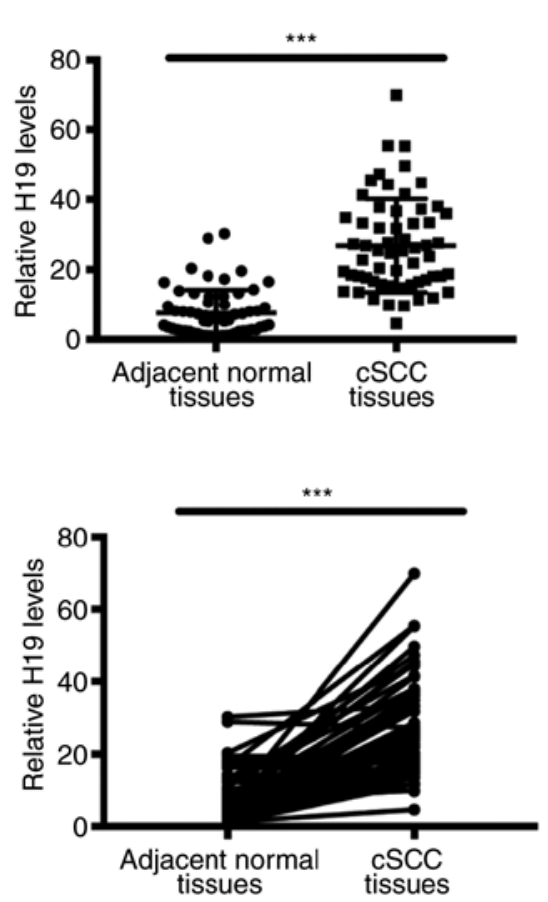

B
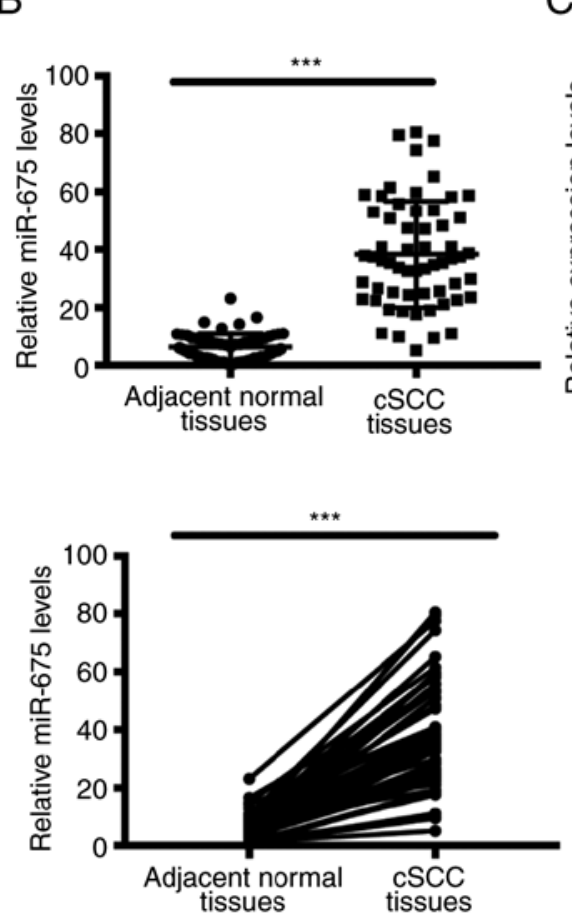

C

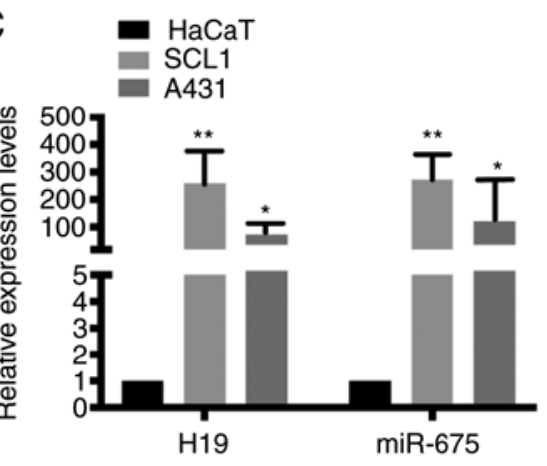

Figure 1. Expression levels of long non-coding RNA H19 and miR-675 were analyzed in cSCC tissues and cell lines and the relationship between H19 and miR-675 with cSCC cells was elucidated. Expression levels of (A) H19 and (B) miR-675 in 60 cSCC tissues and adjacent normal tissues were analyzed using RT-qPCR. (C) Expression levels of H19 and miR-675 were analyzed in SCL1, A431 and HaCaT cells using RT-qPCR. ${ }^{*} \mathrm{P}<0.05,{ }^{* *} \mathrm{P}<0.01$ and ${ }^{* * *} \mathrm{P}<0.001 . \mathrm{miR}$, microRNA; cSCC, cutaneous squamous cell carcinoma; RT-qPCR, reverse transcription-quantitative PCR.

Terminal deoxynucleotidyl transferase dUTP nick end labeling assay. Apoptosis-related DNA fragmentation was analyzed by One Step TUNEL Apoptosis Assay kit (Beyotime Institute of Biotechnology) according to the manufacturer's protocol. Briefly, cells $\left(1 \times 10^{6}\right.$ cells/well) were cultured on the coverslips, washed with PBS and fixed with ice-cold $4 \%$ paraformaldehyde for $30 \mathrm{~min}$ at room temperature. Subsequently, the terminal deoxynucleotidyl transferase (a template-independent polymerase) was used to incorporate nucleotides at the DNA cleavage site. Following the incubation, the nuclei were stained with DAPI at room temperature for $1 \mathrm{~h}$ and fluorescence images were obtained in three different fields of view of each coverslip using a fluorescence microscope (magnification, x200).

Dual-luciferase reporter assay. Wild-type (WT) H19 and p53 3'-untranslated region (UTR) sequences containing miR-675 binding sites were separately cloned into the pGL4-basic vectors (Promega Corporation) to generate pGL4-H19-WT and pGL4-p53-WT vectors, respectively. In addition, the miR-675 binding site was separately mutated into $\mathrm{H} 19$ and $\mathrm{p} 53$ fragments, which were then cloned into pGL4 vectors to obtain pGL4-H19-mutant (MUT) and pGL4-p53-MUT vectors, respectively. In brief, $\mathrm{HaCaT}$ cells were seeded in 96-well plates and reached $70 \%$ confluence overnight. Then HaCaT cells were transfected with the Renilla luciferase reporter plasmids using Lipofectamine ${ }^{\circledR} 2000$ (Invitrogen; Thermo Fisher Scientific, Inc.). Following $24 \mathrm{~h}$ of transfection, the relative luciferase activities were measured using a Dual-Luciferase Reporter assay system (Promega Corporation), according to the manufacturer's protocol. Renilla luciferase activity was normalized to firefly luciferase expression. All experiments were performed in triplicate and independently repeated three times.

Statistical analysis. Online publicly available algorithms (microRNA.org) were used to predict the targets of miR-675 (24). GraphPad Prism 7 (GraphPad Software, Inc.) was used to analyze the data; measurement data were expressed as the mean \pm standard deviation $(\mathrm{x} \pm \mathrm{s})$. Differences between groups were compared using Student's unpaired t-test or ANOVA followed by Sidak's post hoc test. $\mathrm{P}<0.05$ was considered to indicate a statistically significant difference.

\section{Results}

H19 and miR-675 expression levels are upregulated in cSCC tissues and cell lines. To determine the potential function of H19 and miR-675 in cSCC, the mRNA expression levels of $\mathrm{H} 19$ and miR-675 in cSCC tissues and cell lines were analyzed using RT-qPCR. A total of 60 patient samples were used in the present research. Both $\mathrm{H} 19$ and miR-675 expression levels were significantly upregulated in tumor tissues from cSCC compared with adjacent normal tissues (Fig. 1A and B). Similarly, the expression levels of $\mathrm{H} 19$ and miR-675 were also upregulated in the SCC cell lines, SCL1 and A431 (Fig. 1C).

miR-675 targets both $H 19$ and p53 in cSCC. Using online publicly available algorithms (microRNA.org), miR-675 targets were predicted. The results revealed the putative binding site of miR-675 in the 3'UTR of H19 and p53. To determine whether H19 may interact with miR-675 to affect 
A

LnCRNA H19-WT 5'-ccCGCAGCACCCA-CC--CCGCACCg-3'

miR-675-5p 3'- guGACACCCGGGAGAGGCGUGGu-5'

LncRNA H19-Mut 5'- ccCGCAGCACCCACCGGCGUGGg-3'

B
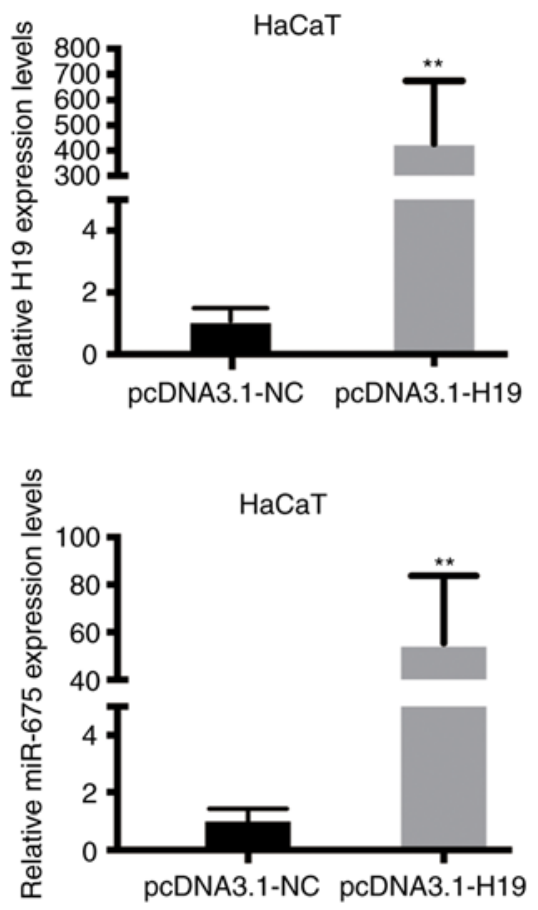

$\mathrm{D}$

p53-WT

miR-675-5p

p53-Mut
C
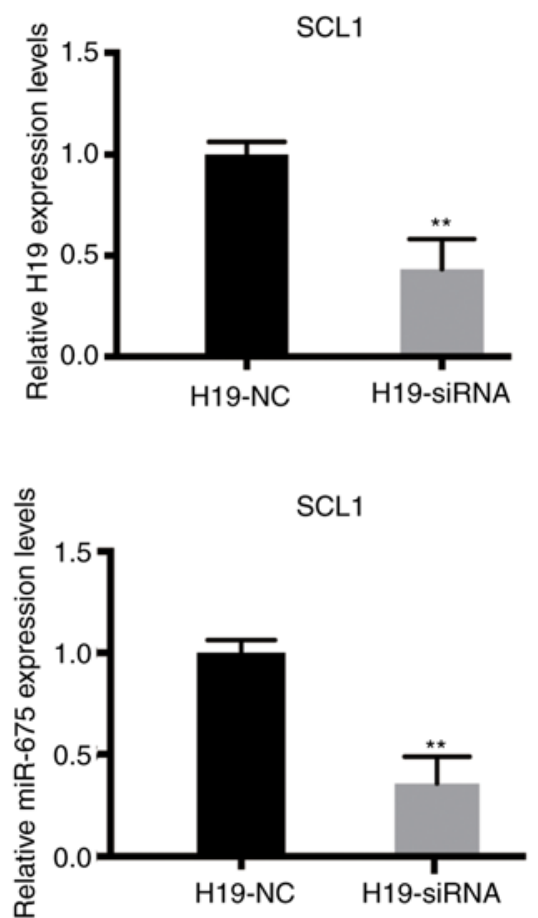

Mimic-NC

miR-675 mimic

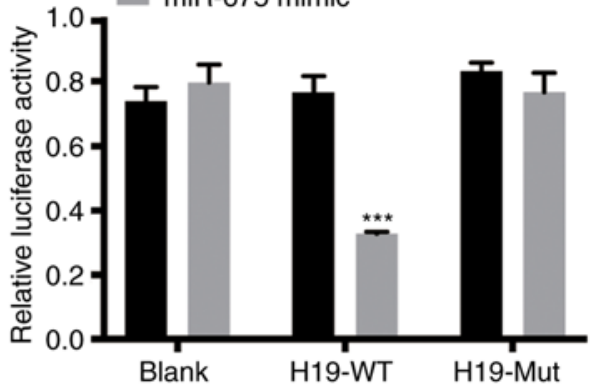

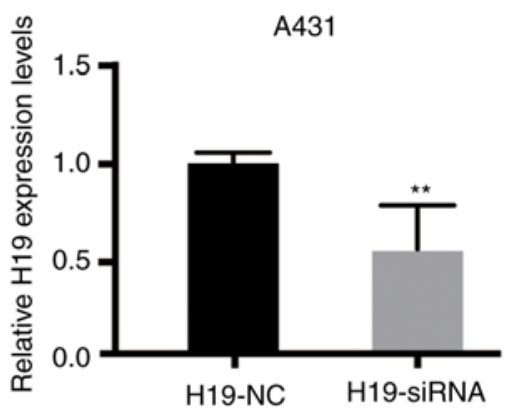
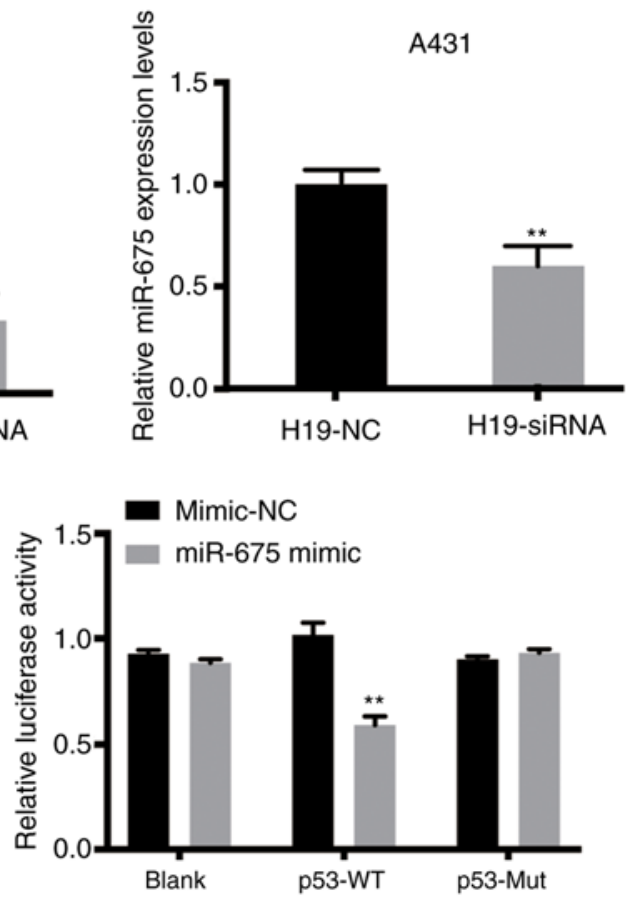

Figure 2. Both H19 and p53 share complementary binding sites with miR-675. (A) Binding sites between miR-675 and p53 were identified. A dual-luciferase reporter assay was subsequently conducted to verify the relationship between miR-675 and p53. (B) H19 and miR-675 expression levels in HaCaT cells transfected with pcDNA3.1-H19 were significantly upregulated compared with the pcDNA3.1-NC group. (C) H19 and miR-675 expression levels in SCL1 and A431 cells transfected with H19-siRNA were significantly downregulated compared with the H19-NC group. (D) Binding sites between miR-675 and p53 were identified. A dual-luciferase reporter assay was conducted to verify the relationship between miR-675 and $\mathrm{p} 53$. ${ }^{* * *} \mathrm{P}<0.01$ and ${ }^{* * * *} \mathrm{P}<0.001$. miR, microRNA; NC, negative control; siRNA, small interfering RNA; WT, wild-type; Mut, mutant.

the molecular mechanism of cSCC cell migration and invasion, dual-luciferase reporter gene assays were performed. The results revealed that the relative luciferase activity was significantly reduced in $\mathrm{HaCaT}$ cells co-transfected with the H19-WT vector and miR-675 mimic compared with the cells in the H19-WT + mimic-NC and H19-Mut + miR-675 mimic groups (Fig. 2A). As anticipated, the overexpression of $\mathrm{H} 19$ increased the expression levels of miR-675 in HaCaT cells (Fig. 2B). Since H19 expression was upregulated in SCL1 and A431 cells, these two cell lines were transfected with H19-siRNA. RT-qPCR analysis was used to verify the successful siRNA-mediated knockdown of H19 expression, and it was subsequently demonstrated that the inhibition of $\mathrm{H} 19$ significantly downregulated the expression levels of miR-675 


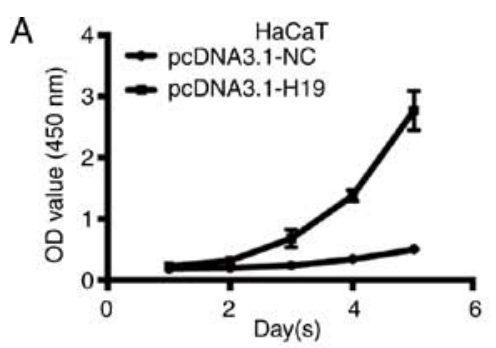

B

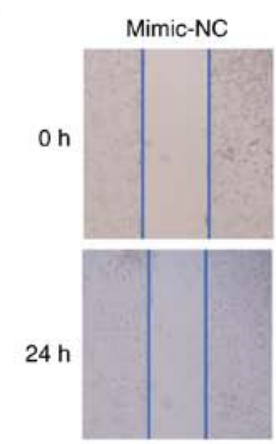

C

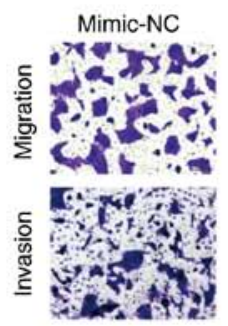

D

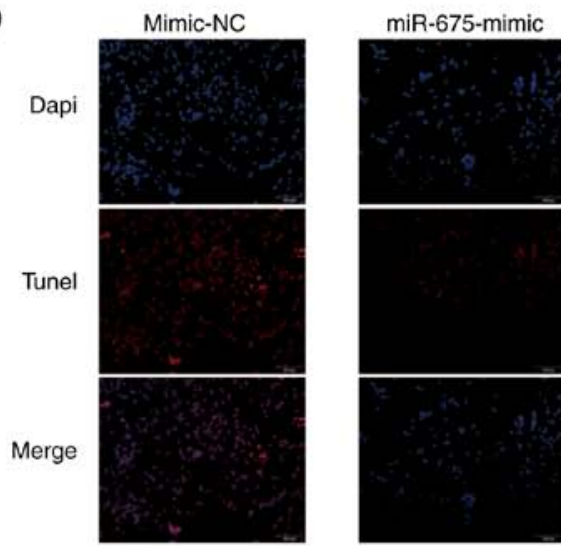

HaCaT
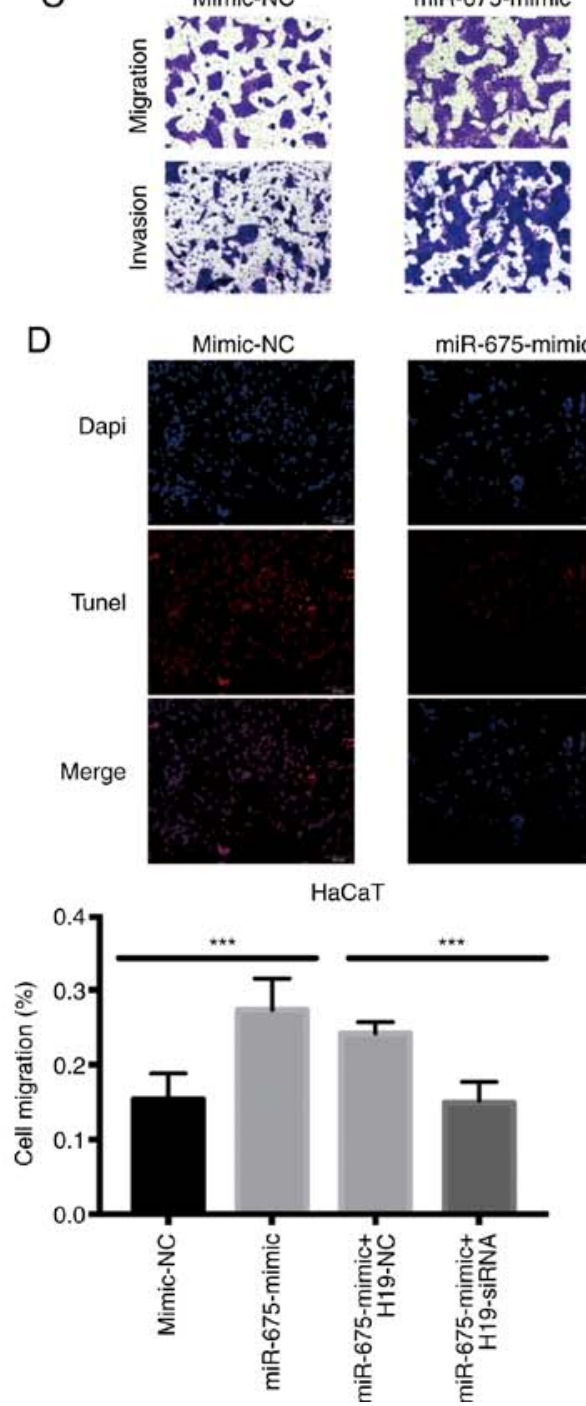

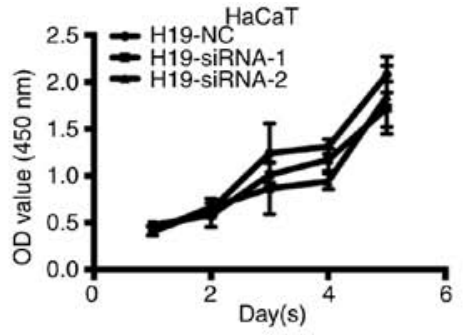

miR-675-mimic + miR-675-mimic + H19-NC

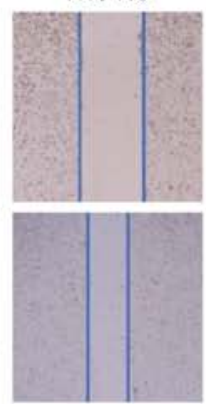

miR-675-mimict H19-NC

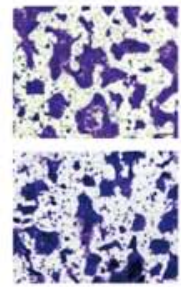

miR-675-mimic+ H19-NC
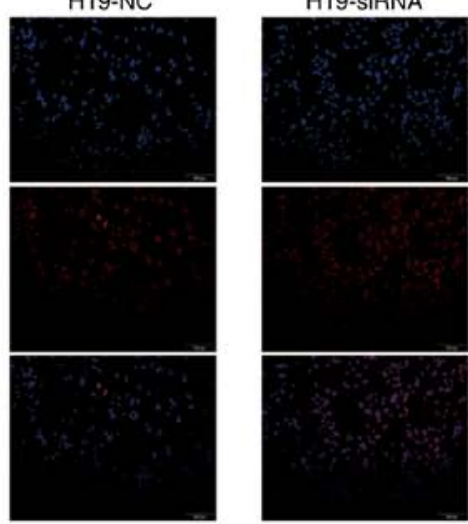

HaCaT

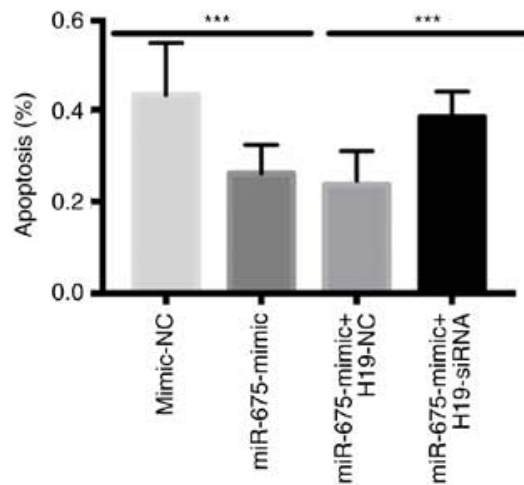

Figure 3. Overexpression of H19 and miR-675 promotes HaCaT cell proliferation, migration and invasion, and inhibits apoptosis. (A) Proliferation of HaCaT cells transfected with pcDNA3.1-H19 and H19-siRNA was analyzed using a Cell Counting Kit-8 assay. (B) A wound healing assay was used to determine the cell migration of HaCaT cells transfected with mimic-NC, miR-675 mimic, miR-675 mimic + H19-NC and miR-675 mimic + H19-siRNA. Magnification, x200. (C) Migration and invasion of HaCaT cells transfected with mimic-NC, miR-675 mimic, miR-675 mimic + H19-NC and miR-675 mimic + H19-siRNA were analyzed using Transwell assays. Magnification, x200. (D) TUNEL assays were used to determine apoptosis in HaCaT cells transfected with mimic-NC, miR-675 mimic, miR-675 mimic + H19-NC and miR-675 mimic + H19-siRNA. Magnification, $x 200 .^{* * *} \mathrm{P}<0.001$. miR, microRNA; siRNA, small interfering RNA; NC, negative control. 
in both cSCC cell lines (Fig. 2C). Moreover, microRNA.org was used to predict that miR-675 could bind to the 3'-UTR of p53. Dual-luciferase reporter assays were subsequently performed to verify the association between miR-675 and p53. The relative luciferase activity was significantly decreased in HaCaT cells in the p53-WT + miR-675 mimic group compared with the p53-Mut + miR-675 mimic and p53-WT + mimic-NC groups $(\mathrm{P}<0.05$; Fig. 2D). These findings suggested that miR-675 may target both $\mathrm{H} 19$ and p53 in HaCaT and SCC cells.

H19/miR-675 axis promotes the proliferation, migration and invasion, but inhibits apoptosis in HaCaT cells. Both H19 and miR-675 were hypothesized to regulate cell proliferation, migration and invasion in $\mathrm{cSCC}$. Therefore, CCK-8, wound healing and Transwell assays were conducted to determine the involvement of the H19/miR-675 axis in these biological functions. The overexpression of H19 significantly increased the proliferation of $\mathrm{HaCaT}$ cells. Conversely, following the confirmation of the successful siRNA-mediated knockdown of $\mathrm{H} 19$, the proliferation of $\mathrm{HaCaT}$ cells transfected with H19-siRNA was revealed to be significantly decreased (Fig. 3A). To determine whether miR-675 served a role in H19-induced cSCC cell migration, HaCaT cells were co-transfected with H19 siRNA and miR-675 mimic, and the migration was analyzed using wound healing and Transwell assays. The miR-675 expression levels were demonstrated to be upregulated following the transfection with miR-675 mimics. Following the co-transfection of miR-675 mimic and H19-siRNA, the migration was decreased in $\mathrm{HaCaT}$ cells (Fig. 3B). Moreover, H19-siRNA could reverse the miR-675 mimic-induced increase in migration and invasion of HaCaT cells, as determined using Transwell assays (Fig. 3C). The levels of apoptosis were also detected using a TUNEL assay following the transfection of HaCaT cells with the miR-675 mimic and H19-siRNA. As revealed in Fig. 3D, H19-siRNA could partially reverse the miR-675 mimic-induced reduction in apoptosis compared with the mimic-NC group (Fig. 3D).

H19 and miR-675 knockdown suppresses the proliferation, migration and invasion, and promotes apoptosis in SCC cells. To further validate that $\mathrm{H} 19$ bound to and sequestered miR-675 to regulate cell migration and proliferation, CCK-8, wound healing and Transwell assays were performed following the overexpression of $\mathrm{H} 19$ and knockdown of miR-675 in SCC cells. Following H19-siRNA transfection, the results of the CCK-8 assay revealed that the cell proliferation ability was significantly decreased (Fig. 4A). In addition, the overexpression of H19 counteracted the miR-675 inhibitor-induced inhibition of cell migration, as observed in the wound healing (Fig. 4B) and Transwell (Fig. 4C) assays, which clarified that H19 could rescue the inhibitive effect of miR-675 inhibitor on cSCC cell migration and invasion. The results of the TUNEL assay demonstrated that pcDNA3.1-H19 reversed the increase in cell apoptosis induced by the miR-675 inhibitor in cSCC cells (Fig. 4D). Thus, the co-transfection with miR-675 inhibitor and pcDNA3.1-H19 could markedly reverse the effect of the miR-675 inhibitor on the proliferation, migration and invasion of cSCC cells. Furthermore, the transfection with pcDNA3.1-H19 could weaken the effects of the miR-675 inhibitor on cSCC cell apoptosis.

p53 is a direct target gene of the H19/miR-675 axis in cSCC. To determine the efficiency of the overexpression or knockdown of H19 on the expression levels of p53 in HaCaT, SCL1 and A431 cells, gain-of-the-function experiments were performed in HaCaT cells overexpressing $\mathrm{H} 19$ and loss-of-function experiments were performed by transfecting H19-siRNA into HaCaT, SCL1 and A431 cells. A previous study demonstrated that WT p53 directly upregulated the expression levels and subsequently activated Bax, which suggested the presence of a complex interaction between Bax, Bcl-2 and p53 during cell proliferation and apoptosis (25). In HaCaT cells, p53 and Bax expression levels were significantly downregulated, while Bcl-2 expression levels were upregulated following the overexpression of H19. Conversely, the transfection with H19-siRNA significantly upregulated the expression levels of p53 and Bax, while decreasing the expression levels of Bcl-2 in HaCaT, SCL1 and A431 cells (Fig. 5A and B). These results indicated that the alterations in $\mathrm{H} 19$ expression levels may be associated with the expression levels of miR-675, which may subsequently regulate p53 expression in cSCC.

To further determine the underlying regulatory mechanism, miR-675 was overexpressed using a miR-675 mimic and knocked down with a miR-675 inhibitor in HaCaT, SCL1 and A431 cells (Fig. 5C and D), and the expression levels of p53, Bax and Bcl-2 were analyzed using western blotting. The expression levels of p53 and Bax were downregulated following the transfection with the miR-675 mimic and upregulated following the transfection with the miR-675 inhibitor. In addition, while Bcl-2 expression levels were upregulated following the transfection with the miR-675 mimic, the expression levels were downregulated following the transfection with the miR-675 inhibitor. These results suggested that p53 may be a target of miR- 675 and may be negatively regulated by the H19/miR-675 axis.

Effect of $H 19$ and miR-675 on the EMT of cSCC cell lines. EMT is an important process for tumor invasion and metastasis. Thus, western blotting was used to determine the effects of H19 and miR-675 on the expression levels of the EMT-related markers, E-cadherin, vimentin and N-cadherin. The overexpression of miR-675 in HaCaT cells upregulated the expression levels of $\mathrm{N}$-cadherin and vimentin, and downregulated the expression levels of E-cadherin. Conversely, the knockdown of miR-675 markedly downregulated N-cadherin and vimentin expression levels, while the expression levels of E-cadherin were upregulated (Fig. 6A and B). Similarly, in SCL1 and A431 cells transfected with the miR-675 mimic, the protein expression levels of $\mathrm{N}$-cadherin and vimentin were upregulated, while those of E-cadherin were downregulated (Fig. 6C and D). The opposite trends were observed following the transfection of cells with the miR-675 inhibitor. Furthermore, p53 could reverse the effects of H19 on the EMT processes. HaCaT cells co-transfected with pcDNA3.1-H19 and pcDNA3.1-p53 suppressed the progression of EMT (Fig. 6E). Furthermore, cSCC cells co-transfected with H19-siRNA and p53-siRNA could promote the EMT process inhibited by H19-siRNA (Fig. 6F). Collectively, these findings 

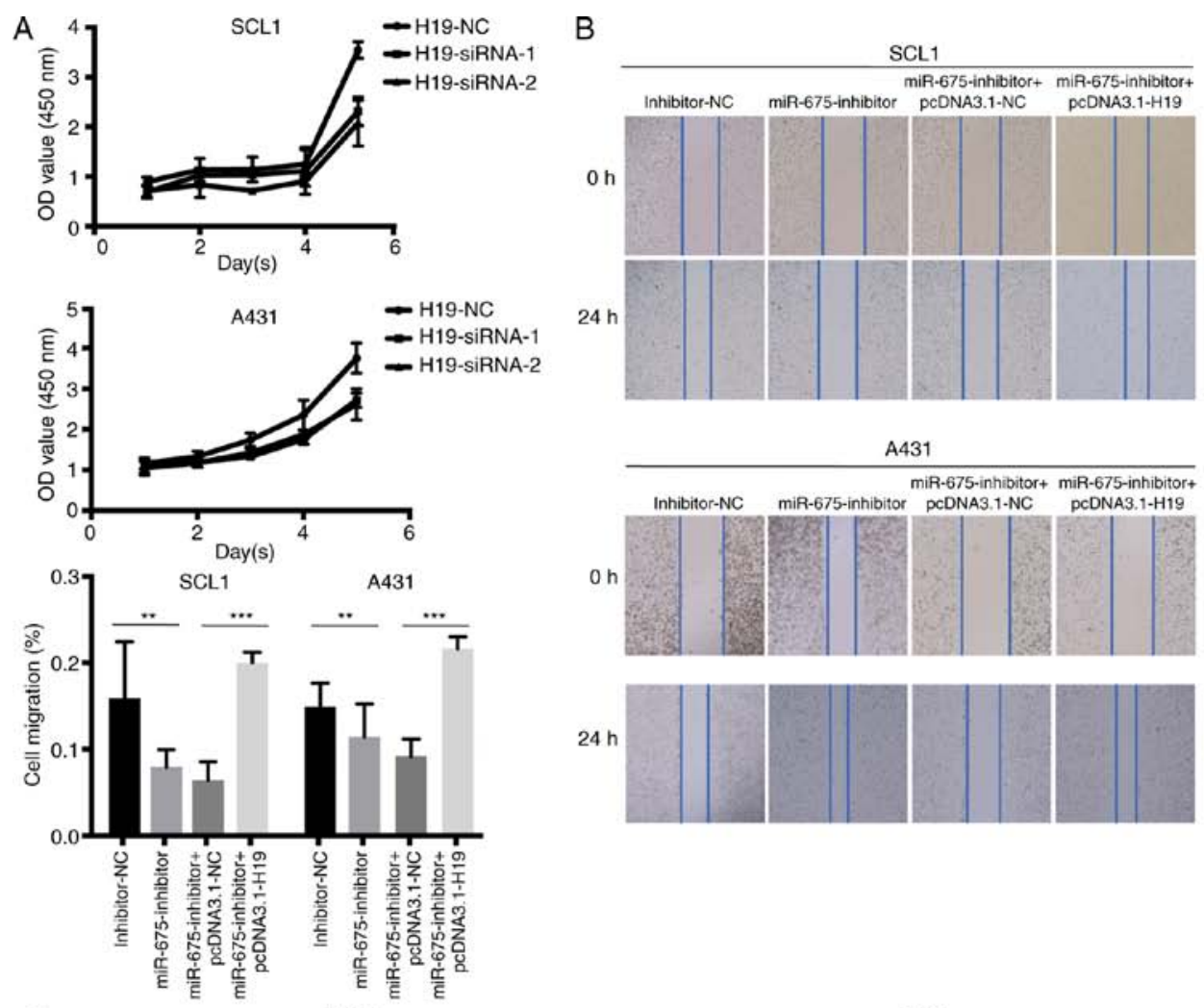

C

SCL1
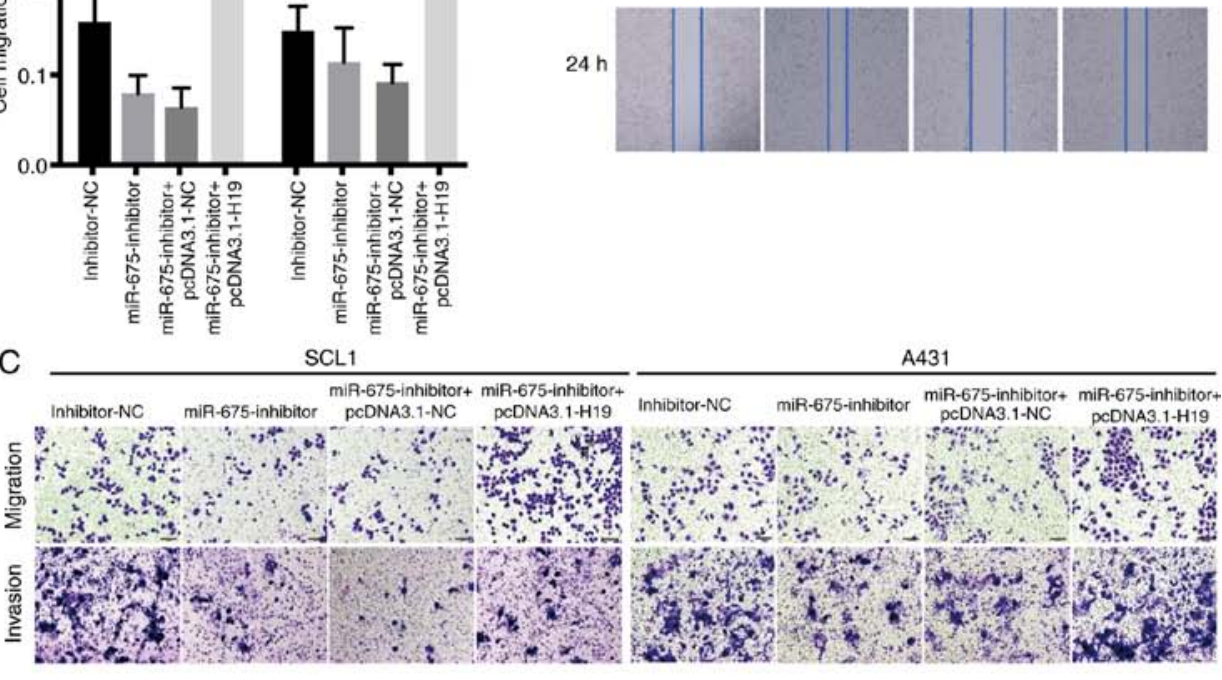

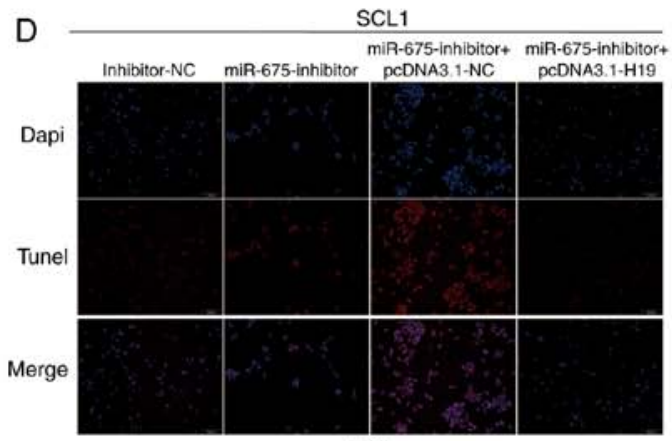

A431

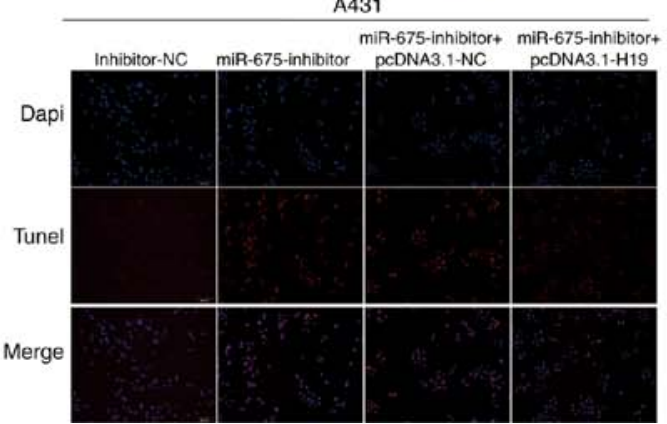

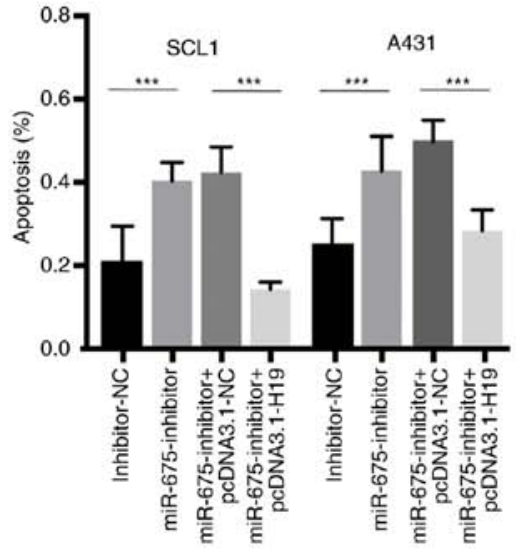

Figure 4. H19 and miR-675 knockdown inhibits cSCC cell proliferation, migration and invasion, and promotes apoptosis. (A) Proliferation of SCL1 and A431 cells transfected with H19-siRNAs was detected using a Cell Counting Kit-8 assay. (B) A wound healing assay was used to analyze the migration of cSCC cells transfected with inhibitor-NC, miR-675 inhibitor, miR-675-inhibitor + pcDNA3.1-NC and miR-675 inhibitor + pcDNA3.1-H19. Magnification, x200. (C) Migration and invasion of cSCC cells transfected with inhibitor-NC, miR-675 inhibitor, miR-675-inhibitor + pcDNA3.1-NC and miR-675 inhibitor + pcDNA3.1-H19 were analyzed using Transwell assays. Magnification, x200. (D) TUNEL assays were used to determine apoptosis in cSCC cells transfected with inhibitor-NC, miR-675 inhibitor, miR-675-inhibitor + pcDNA3.1-NC and miR-675 inhibitor + pcDNA3.1-H19. Magnification, x200. ${ }^{* *} \mathrm{P}<0.01$ and ${ }^{* * *} \mathrm{P}<0.001$. miR, microRNA; siRNA, small interfering RNA; NC, negative control; cSCC, cutaneous squamous cell carcinoma. 
A

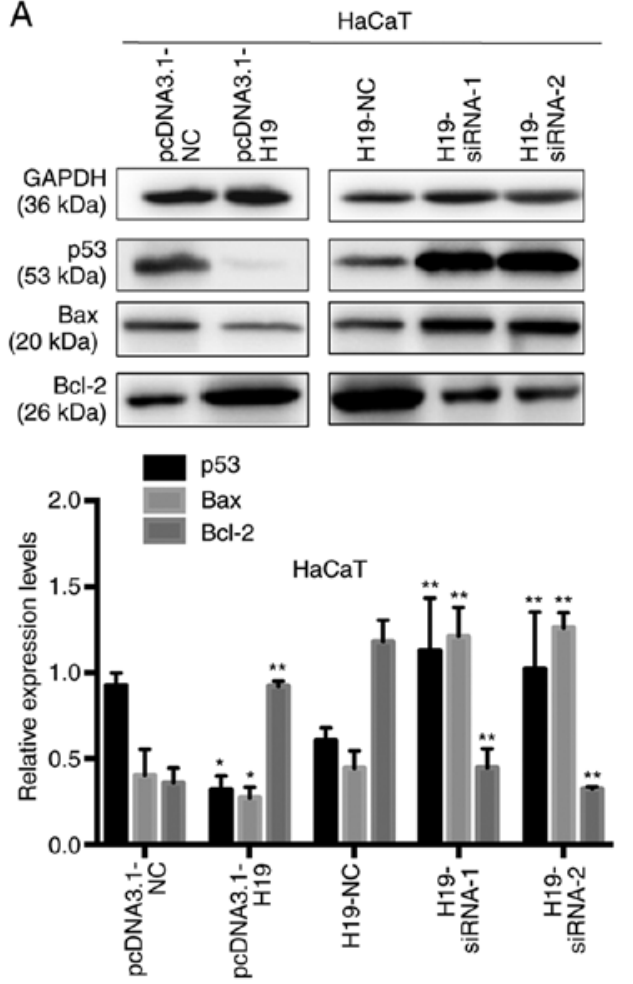

C
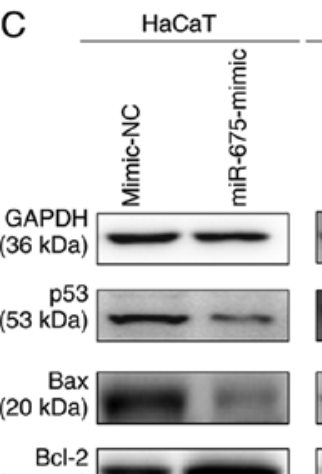

$\mathrm{Bcl}-2$
$(26 \mathrm{kDa})$
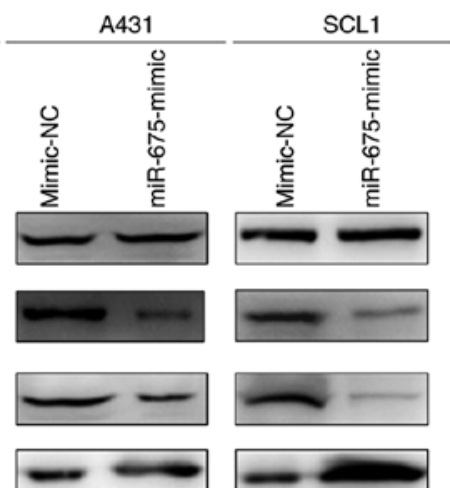

B
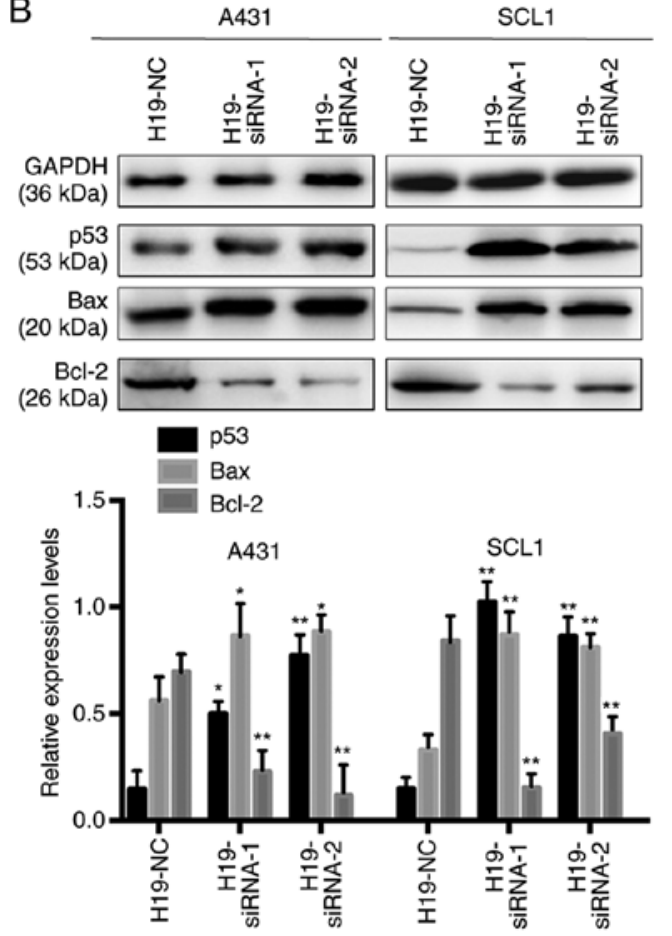

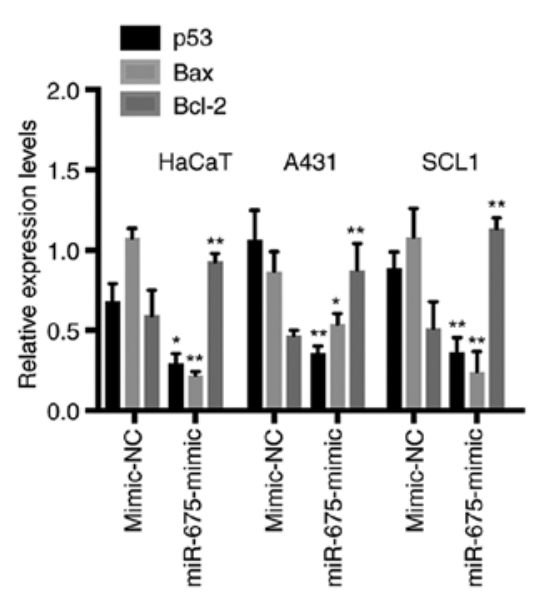

D
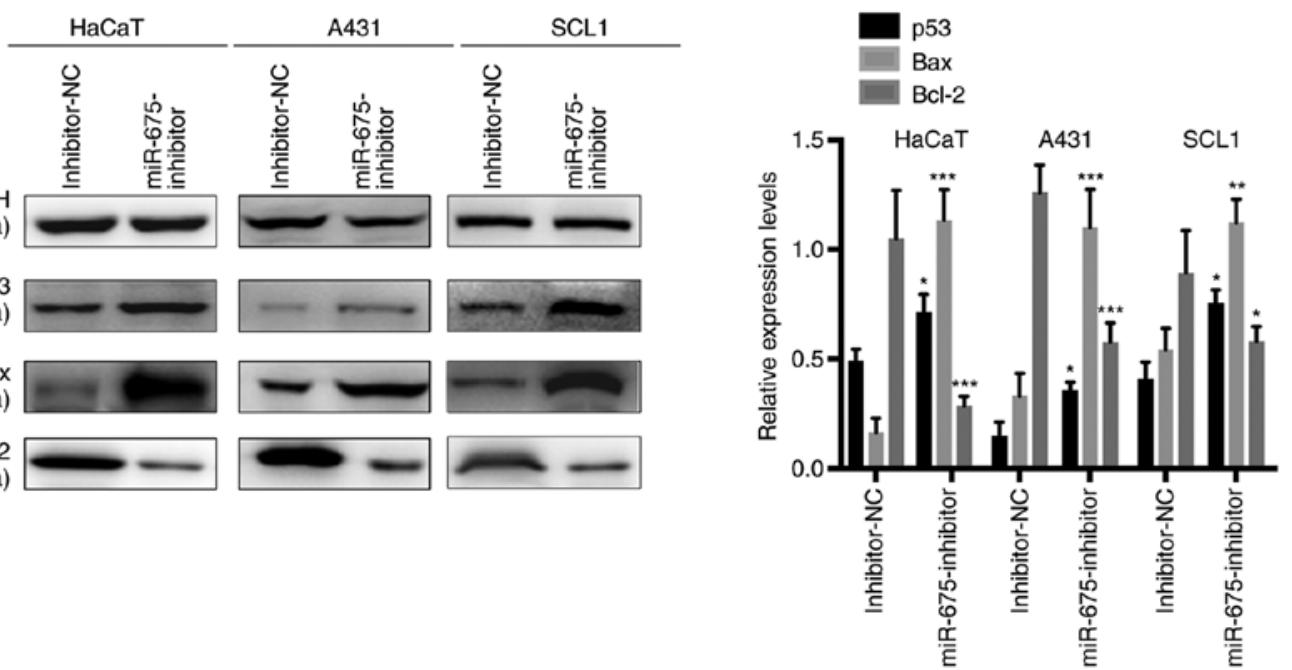

Figure 5. p53 is associated with the H19/miR-675 axis in cutaneous squamous cell carcinoma. (A) Protein expression levels of p53, Bax and Bcl-2 in HaCaT cells were analyzed using western blotting following the transfection with pcDNA3.1-H19 and H19-siRNAs. (B) Protein expression levels of p53, Bax and Bcl-2 in A431 and SCL1 cells were analyzed using western blotting following the transfection with H19-siRNAs. (C) Western blotting was used to determine the protein expression levels of p53, Bax and Bcl-2 in HaCaT, A431 and SCL1 cells transfected with (C) mimic-NC and miR-675 mimic and (D) inhibitor-NC and miR-675 inhibitor. ${ }^{*} \mathrm{P}<0.05,{ }^{* *} \mathrm{P}<0.01$ and ${ }^{* * *} \mathrm{P}<0.001$. miR, microRNA; siRNA, small interfering RNA; NC, negative control. 
A
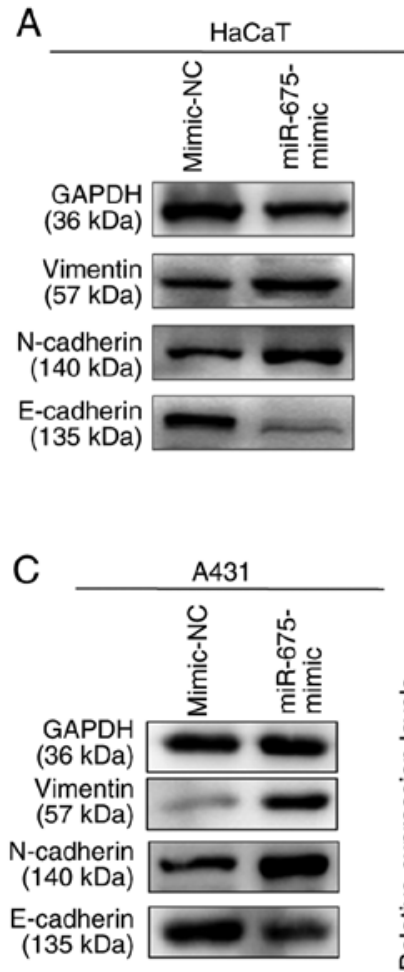

D

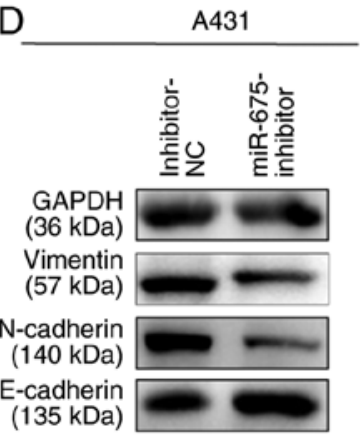

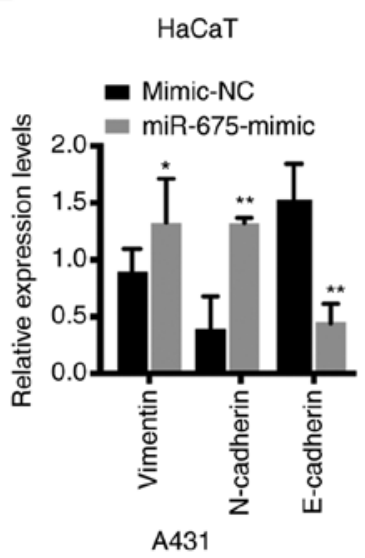
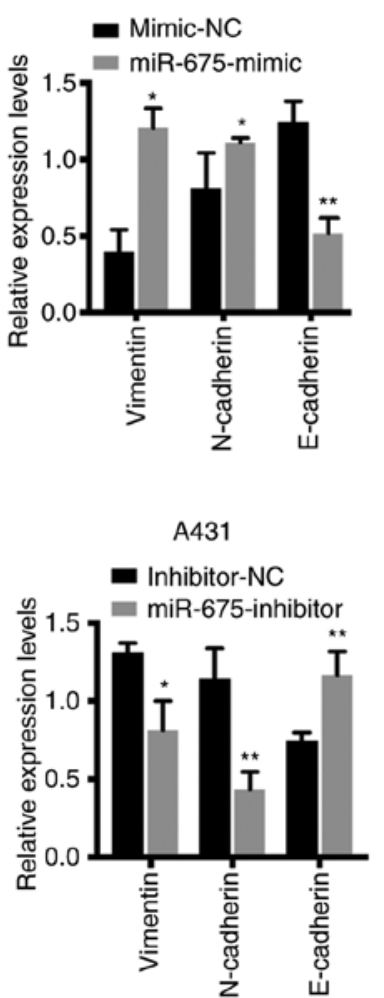

B
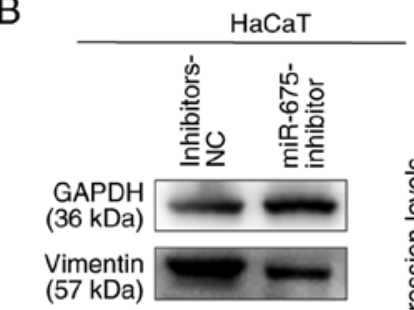

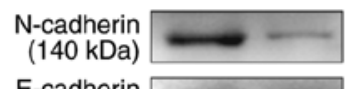

E-cadherin $=$

$(135 \mathrm{kDa})$
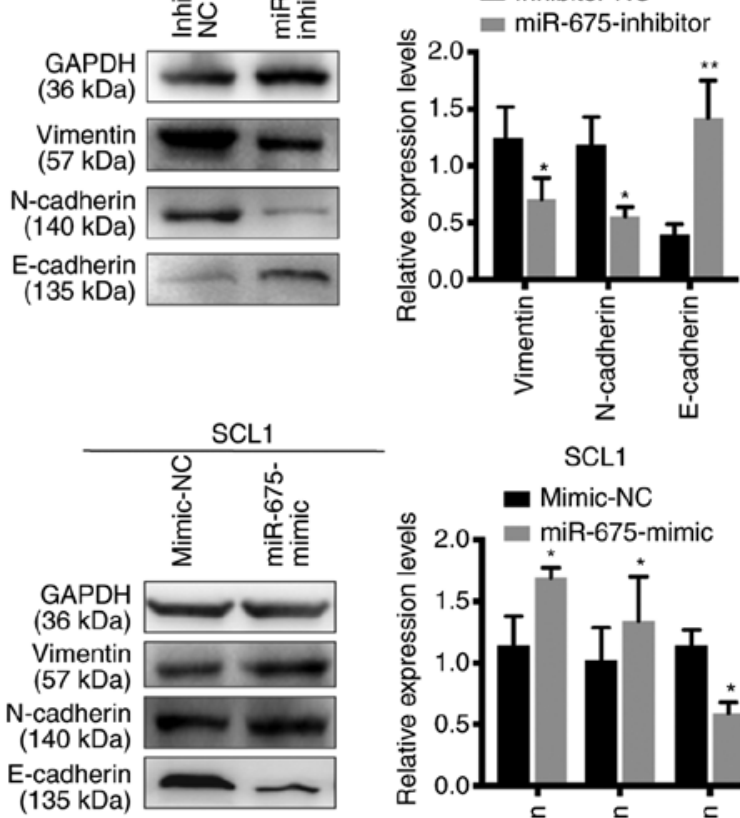

$\mathrm{HaCaT}$

- Inhibitor-NC

miR-675-inhibitor

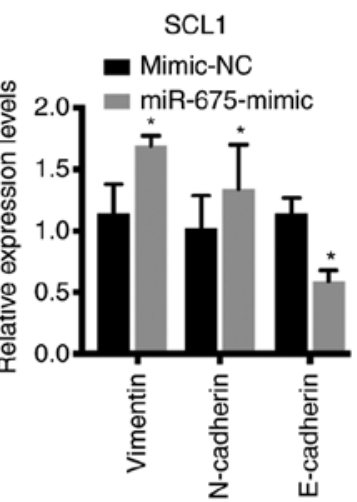

SCL1

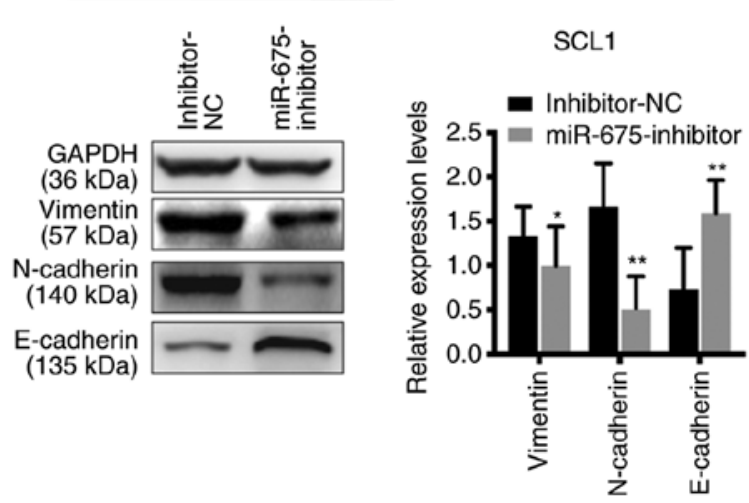

E

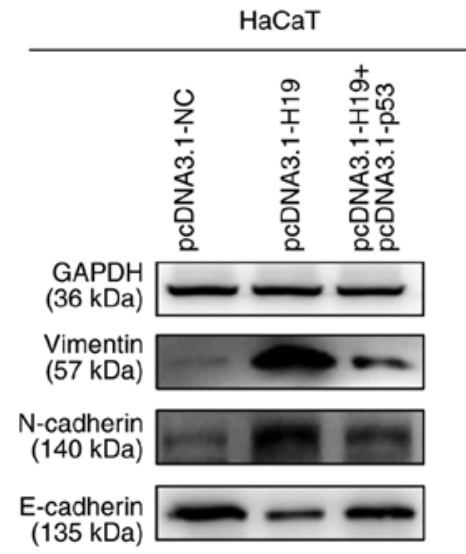

$\mathrm{F}$

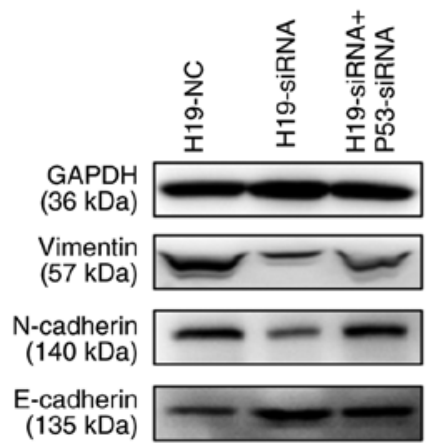

SCL1

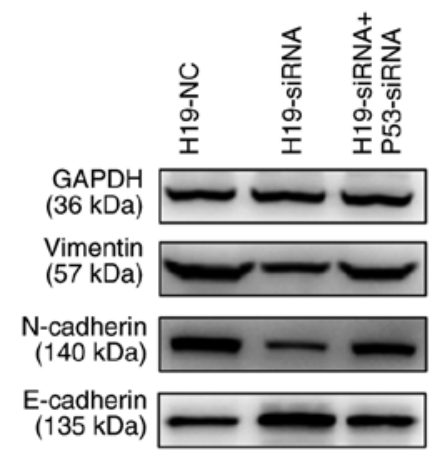

Figure 6. Effect of H19 and miR-675 on the epithelial-mesenchymal transition of cutaneous squamous cell carcinoma cell lines. Expression levels of vimentin, $\mathrm{N}$-cadherin and E-cadherin were analyzed using western blotting in HaCaT cells transfected with (A) miR-675 mimic or mimic-NC and (B) miR-675 inhibitor and inhibitor-NC. Expression levels of vimentin, N-cadherin and E-cadherin were analyzed using western blotting in SCL1 and A431 cells transfected with (C) miR-675 mimic and mimic-NC and (D) miR-675 inhibitor and inhibitor-NC. (E) Expression levels of vimentin, N-cadherin and E-cadherin were analyzed using western blotting in $\mathrm{HaCaT}$ cells co-transfected with pcDNA3.1-H19 and pcDNA3.1-p53. (F) Expression levels of vimentin, N-cadherin and E-cadherin were analyzed using western blotting in A431 and SCL1 cells co-transfected with H19-siRNA and p53-siRNA. ${ }^{*} \mathrm{P}<0.05$ and ${ }^{* *} \mathrm{P}<0.01$. miR, microRNA; NC, negative control; siRNA, small interfering RNA. 
suggested that H19 and miR-675 may promote the EMT process in $\mathrm{cSCC}$.

\section{Discussion}

To the best of our knowledge, the present study was the first to report that the expression levels of H19 were upregulated in cSCC tissues and cells compared with normal adjacent tissues and keratinocyte cells, respectively. In addition, the present study determined the functional association between H19 and p53; and hypothesized that miR-675, a transcript of H19, may serve an intermediary role in affecting the expression levels of p53 and EMT-related markers. The results of the cell functional assays demonstrated that both $\mathrm{H} 19$ and miR-675 expression levels were significantly upregulated in cSCC cell lines. Moreover, the knockdown of H19 and miR-675 expression inhibited cSCC cell proliferation, migration and invasion, and partially downregulated p53 expression levels. Furthermore, western blotting revealed that the effect of silencing of H19 expression on the EMT process could be reversed by p53 in cSCC cell lines. Altogether, these data suggested that the upregulation of H19 may promote cSCC tumorigenesis and progression.

Cutaneous squamous cell carcinoma originates from keratinocytes and is the second most common type of non-melanoma skin tumor (26). An increasing number of studies have reported an association between lncRNAs and cSCC (27). Accumulating evidence has revealed that $\mathrm{H} 19$, as a cancer-related lncRNA, served an important role in physiological activities and pathological mechanisms $(16,28,29)$. For example, H19 was reported to act as an oncogene in bladder, gastric, breast and thyroid cancer, in addition to glioma (15,30-33). In colorectal cancer, H19 promoted the cell proliferation, migration and invasion of cancer cells through sponging miR-138 and subsequently upregulating the expression levels of HMGA1 (18). In cholangiocarcinoma, upregulated expression levels of $\mathrm{H} 19$ were associated with IкB phosphorylation and the transport of the p50/p65 heterodimer to the nucleus, which led to the upregulation of the expression levels of genes involved in the NF- $\mathrm{NB}$ signaling pathway (34). In addition, $\mathrm{H} 19$ expression levels were also revealed to be downregulated in hepatocellular cancer (35). However, the underlying mechanisms of $\mathrm{H} 19$ dysregulation in $\mathrm{CSCC}$ remain poorly understood. The findings of the present study verified the effects of IncRNA H19 on promoting the tumorigenesis of cSCC cells, in which the upregulation of $\mathrm{H} 19$ expression promoted cSCC cell proliferation, migration and invasion and prevented apoptosis.

A previous study suggested that $\mathrm{H} 19$ may act as a precursor of miR-675 at the post-transcriptional level (20). In non-small cell lung cancer cells, the knockdown of H19 markedly downregulated miR-675 expression levels. Furthermore, the H19/miR-675 axis was discovered to be upregulated post-hypoxia exposure (COPD) and thus, was suggested as a potential novel therapeutic tool for the management of non-small cell lung cancer (36).

The roles of IncRNAs in cSCC have been previously investigated to improve the current understanding of mutations in $\mathrm{CSCC}$ and lay the foundations for targeted therapy in cSCC (37). A recent review summarized that the expression levels of lncRNAs, such as p38 inhibited cSCC-associated lincRNA, long intergenic non-protein coding RNA (LINC) 00319, testis associated oncogenic lncRNA, AK144841, metastasis associated lung adenocarcinoma transcript 1 , LINC01048 and HOX transcript antisense RNA were upregulated, while the expression levels of TINCR ubiquitin domain containing, LINC00520 and growth arrest specific 5 were downregulated in $\mathrm{cSCC}$ (27). However, to the best of our knowledge, the function of $\mathrm{H} 19$ has not been reported in cSCC. Furthermore, previous studies have also revealed that several miRNAs, such as miR-21, miR-205, miR-365, miR-31, miR-135b, miR-142, and miR-186, exerted oncogenic functions while other miRNAs, including miR-20a, miR-203, miR-181a, miR-125b, miR-34a, miR-148a, miR-214, miR-124, miR-204, and miR-199a served as tumor suppressors (38). However, the underlying mechanisms of miR-675 in cSCC remain largely unknown. The results of the present study indicated that the overexpression of H19 may upregulate miR-675 expression levels, and that the knockdown of H19 inhibited cell growth, migration and cell invasion by regulating miR-675 expression in cSCC cell lines.

EMT is a crucial process during the progression of various types of cancer and was discovered to serve an important role in the primary epithelial cancer and metastasis into the adjacent organs and blood vessels (39). E-cadherin is localized on the surfaces of epithelial cells in regions of cell-cell contact known as adherens junctions, and has been reported to be closely associated with tumor invasiveness and cancer metastasis $(40,41)$. Vimentin was revealed to regulate cell migration through recycling of endocytosed cell adhesion receptors (42). In addition, $\mathrm{N}$-cadherin acts as a mesenchymal marker (43). Thus, the present study aimed to determine the association between H19 and EMT in cSCC by investigating the expression levels of these proteins. The western blotting results revealed that the expression levels of these important EMT markers, E-cadherin, $\mathrm{N}$-cadherin and vimentin were significantly affected by the H19/miR-675 axis in cSCC cell lines. Furthermore, the findings suggested that the overexpression of p53 rescued the effects induced by $\mathrm{H} 19$ in cSCC. Therefore, the results of the present study indicated that the H19/miR-675 axis may promote metastasis by affecting the EMT process. To the best of our knowledge, the present study was the first to provide evidence of the function of the H19/miR-675/p53 axis in cSCC.

In conclusion, the findings of the present study suggested that H19 may act as an oncogenic lncRNA in cSCC proliferation, migration and invasion via modulating miR-675, and therefore may be associated with a poor prognosis in $\mathrm{cSCC}$. These data suggested that $\mathrm{H} 19$ may represent a potential target for cSCC treatment and offered novel insights for further diagnostic and therapeutic medical research to investigate the role of $\mathrm{H} 19$ in $\mathrm{cSCC}$.

\section{Acknowledgements}

Not applicable.

\section{Funding}

No funding was received. 


\section{Availability of data and materials}

The analyzed data sets generated during the study are available from the corresponding author on reasonable request.

\section{Authors' contributions}

WZ and $\mathrm{KZ}$ conducted the research and performed the experiments. WZ, KZ, XZ and CW performed the data collection and analyses. $\mathrm{WZ}$ and $\mathrm{KZ}$ designed the experiments and supervised the procedures and wrote the manuscript. $X Z$ and DD performed the surgical excision of skin lesions of patients, collected clinical tissues samples and summarized the information of patients. ZY proposed the research direction, revising the manuscript for important intellectual content. All authors read and approved the manuscript and agree to be accountable for all aspects of the research in ensuring that the accuracy or integrity of any part of the work are appropriately investigated and resolved.

\section{Ethics approval and consent to participate}

The present study was approved by the Ethics Committee of Xinhua Hospital, School of Medicine, Shanghai Jiao Tong University (Shanghai, China). All patients provided written informed consent prior to participation.

\section{Patient consent for publication}

Not applicable.

\section{Competing interests}

The authors declare that they have no competing interests.

\section{References}

1. Motaparthi K, Kapil JP and Velazquez EF: Cutaneous squamous cell carcinoma: Review of the eighth edition of the American Joint Committee on Cancer staging guidelines, prognostic factors, and histopathologic variants. Adv Anat Pathol 24: 171-194, 2017.

2. Ackerman AB and Mones JM: Solar (actinic) keratosis is squamous cell carcinoma. Br J Dermatol 155: 9-22, 2006.

3. Koike Y, Yozaki M, Kuwatsuka Y and Utani A: Epithelialmesenchymal transition in Bowen's disease when arising de novo and acquiring invasive capacity. J Dermatol 45: 748-750, 2018.

4. Ishitsuka Y, Kawachi Y, Taguchi S, Maruyama H, Nakamura Y, Fujisawa Y, Furuta J, Nakamura Y, Ishii Y and Otsuka F: Pituitary tumor-transforming gene 1 as a proliferation marker lacking prognostic value in cutaneous squamous cell carcinoma. Exp Dermatol 22: 318-322, 2013.

5. Graindorge S, Cognat V, Johann To Berens P, Mutterer J and Molinier J: Photodamage repair pathways contribute to the accurate maintenance of the DNA methylome landscape upon UV exposure. PLoS Genet 15: e1008476, 2019.

6. Fernandez Figueras MT: From actinic keratosis to squamous cell carcinoma: Pathophysiology revisited. J Eur Acad Dermato Venereol 31 (Suppl 2): S5-S7, 2017.

7. Lobl M, Grinnell M, Phillips A, Abels J and Wysong A: The correlation between immunohistochemistry findings and metastasis in squamous cell carcinoma: A review. Dermatol Surg: Nov 3, 2020 (Epub ahead of print). doi: 10.1097/DSS.0000000000002850.

8. Tian K, Liu W, Zhang J, Fan X, Liu J, Zhao N, Yao C and Miao G: MicroRNA-125b exerts antitumor functions in cutaneous squamous cell carcinoma by targeting the STAT3 pathway. Cell Mol Biol Lett 25: 12, 2020
9. Cerk S, Schwarzenbacher D, Adiprasito JB, Stotz M, Hutterer GC Gerger A, Ling H, Calin GA and Pichler M: Current status of long non-coding RNAs in human breast cancer. Int J Mol Sci 17: 1485, 2016.

10. Hao S, Yao L, Huang J, He H, Yang F, Di Y, Jin C and Fu D: Genome-wide analysis identified a number of dysregulated long noncoding RNA (lncRNA) in human pancreatic ductal adenocarcinoma. Technol Cancer Res Treat 17: 1533034617748429, 2018.

11. Ponzio G, Rezzonico R, Bourget I, Allan R, Nottet N, Popa A, Magnone V, Rios G, Mari B and Barbry P: A new long noncoding RNA (lncRNA) is induced in cutaneous squamous cell carcinoma and down-regulates several anticancer and cell differentiation genes in mouse. J Biol Chem 292: 12483-12495, 2017.

12. Pachnis V, Belayew A and Tilghman SM: Locus unlinked to alpha-fetoprotein under the control of the murine raf and Rif genes. Proc Natl Acad Sci USA 81: 5523-5527, 1984.

13. Zhou W, Ye XL, Xu J, Cao MG, Fang ZY, Li LY, Guan GH, Liu Q, Qian YH and Xie D: The IncRNA H19 mediates breast cancer cell plasticity during EMT and MET plasticity by differentially sponging miR-200b/c and let-7b. Sci Signal 10: eaak9557, 2017.

14. Wu J, Qin Y, Li B, He WZ and Sun ZL: Hypomethylated and hypermethylated profiles of H19DMR are associated with the aberrant imprinting of IGF2 and H19 in human hepatocellular carcinoma. Genomics 91: 443-450, 2008.

15. Li X, Li Q, Jin X, Guo H and Li Y: Long non-coding RNA H19 knockdown inhibits the cell viability and promotes apoptosis of thyroid cancer cells through regulating the PI3K/AKT pathway. Exp Ther Med 18: 1863-1869, 2019.

16. Ghafouri-Fard S, Esmaeili M and Taheri M: H19 lncRNA: Roles in tumorigenesis. Biomed Pharmacother 123: 109774, 2020.

17. Wang WT, Ye H, Wei PP, Han BW, He B, Chen ZH and Chen YQ: LncRNAs H19 and HULC, activated by oxidative stress, promote cell migration and invasion in cholangiocarcinoma through a ceRNA manner. J Hematol Oncol 9: 117, 2016.

18. Yang Q, Wang X, Tang C, Chen X and He J: H19 promotes the migration and invasion of colon cancer by sponging miR-138 to upregulate the expression of HMGA1. Int J Oncol 50: 1801-1809, 2017.

19. Shi G, Li H, Gao F and Tan Q: IncRNA H19 predicts poor prognosis in patients with melanoma and regulates cell growth, invasion, migration and epithelial-mesenchymal transition in melanoma cells. Onco Targets Ther 11: 3583-3595, 2018.

20. Cai X and Cullen BR: The imprinted H19 noncoding RNA is a primary microRNA precursor. RNA 13: 313-316, 2007.

21. Simons M and Raposo G: Exosomes-vesicular carriers for intercellular communication. Curr Opin Cell Biol 21: 575-581, 2009.

22. Kim NH, Lee $\mathrm{CH}$ and Lee AY: H19 RNA downregulation stimulated melanogenesis in melasma. Pigment Cell Melanoma Res 23: 84-92, 2010

23. Livak KJ and Schmittgen TD: Analysis of relative gene expression data using real-time quantitative PCR and the 2(-Delta Delta C(T)) method. Methods 25: 402-408, 2001.

24. Betel D, Wilson M, Gabow A, Marks DS and Sander C: The microRNA.org resource: Targets and expression. Nucleic Acids Res 36 (Database Issue): D149-D153, 2008.

25. Miyashita T and Reed JC: Tumor suppressor p53 is a direct transcriptional activator of the human bax gene. Cell 80: 293-299, 1995.

26. Sand M, Bechara FG, Gambichler T, Sand D, Bromba M, Hahn SA, Stockfleth E and Hessam S: Circular RNA expression in cutaneous squamous cell carcinoma. J Dermatol Sci 83: 210-218, 2016.

27. Wang Y, Sun B, Wen X, Hao D, Du D, He G and Jiang X: The roles of lncRNA in cutaneous squamous cell carcinoma. Front Oncol 10: 158, 2020.

28. Li J, Su T, Zou C, Luo W, Shi G, Chen L, Fang C and Li C: Long non-coding RNA H19 regulates porcine satellite cell differentiation through miR-140-5p/SOX4 and DBN1. Front Cell Dev Biol 8: 518724, 2020.

29. Lecerf C, Peperstraete E, Le Bourhis X and Adriaenssens E: Propagation and maintenance of cancer stem cells: A major influence of the long non-coding RNA H19. Cells 9: 2613, 2020.

30. Hua Q, Lv X, Gu X, Chen Y, Chu H, Du M, Gong W, Wang M and Zhang Z: Genetic variants in IncRNA H19 are associated with the risk of bladder cancer in a Chinese population. Mutagenesis 31: 531-538, 2016.

31. Liu G, Xiang T, Wu QF and Wang WX: Long noncoding RNA H19-derived miR-675 enhances proliferation and invasion via RUNX1 in gastric cancer cells. Oncol Res 23: 99-107, 2016. 
32. Peperstraete E, Lecerf C, Collette J, Vennin C, Raby L, Völkel P, Angrand PO, Winter M, Bertucci F, Finetti P, et al: Enhancement of breast cancer cell aggressiveness by lncRNA H19 and its Mir-675 derivative: Insight into shared and different actions. Cancers (Basel) 12: 1730, 2020.

33. Hu Q, Yin J, Zeng A, Jin X, Zhang Z, Yan W and You Y: H19 functions as a competing endogenous RNA to regulate EMT by sponging miR-130a-3p in glioma. Cell Physiol Biochem 50: 233-245, 2018

34. Yang S, Fang F, Yu X, Yang C, Zhang X, Wang L, Zhu L, Shao K and Zhu T: Knockdown of H19 inhibits the pathogenesis of acne vulgaris by targeting the miR-196a/TLR $2 / N F-\kappa B$ axis Inflammation 43: 1936-1947, 2020.

35. Iempridee T: Long non-coding RNA H19 enhances cell proliferation and anchorage-independent growth of cervical cancer cell lines. Exp Biol Med (Maywood) 242: 184-193, 2017.

36. Zheng ZH, Wu DM, Fan SH, Zhang ZF, Chen GQ and Lu J: Upregulation of miR-675-5p induced by lncRNA H19 was associated with tumor progression and development by targeting tumor suppressor p53 in non-small cell lung cancer. J Cell Biochem 120: 18724-18735, 2019.

37. Tay Y, Rinn J and Pandolfi PP: The multilayered complexity of ceRNA crosstalk and competition. Nature 505: 344-352, 2014.
38. García-Sancha N, Corchado-Cobos R, Pérez-Losada J and Cañueto J: MicroRNA dysregulation in cutaneous squamous cell carcinoma. Int J Mol Sci 20: 2181, 2019.

39. Singh A and Settleman J: EMT, cancer stem cells and drug resistance: An emerging axis of evil in the war on cancer. Oncogene 29: 4741-4751, 2010.

40. Lee JM, Dedhar S, Kalluri R and Thompson EW: The epithelial-mesenchymal transition: New insights in signaling, development, and disease. J Cell Biol 172: 973-981, 2006.

41. Gumbiner BM: Regulation of cadherin-mediated adhesion in morphogenesis. Nat Rev Mol Cell Biol 6: 622-634, 2005.

42. Ivaska J, Vuoriluoto K, Huovinen T, Izawa I, Inagaki M and Parker PJ: PKCepsilon-mediated phosphorylation of vimentin controls integrin recycling and motility. EMBO J 24: 3834-3845, 2005.

43. Wang L and Yu P: miR-300 promotes proliferation and EMT-mediated colorectal cancer migration and invasion by targeting p53. Oncol Rep 36: 3225-3232, 2016.

c) (i) $\odot$ This work is licensed under a Creative Commons Attribution-NonCommercial-NoDerivatives 4.0 International (CC BY-NC-ND 4.0) License. 